\title{
Local and Systemic Effects of Fluoride in Alginate Impression Materials: A Review
}

\author{
Faiez N Hattab
}

\begin{abstract}
Aim: To review local and systemic effects of fluoride (F) in alginate impression materials.

Background: Alginate is the most frequently used impression material in dental practices. The alginate powder contains $\mathrm{F}$ compounds as an integral ingredient.

Materials and methods: Reviewed articles are categorized into three main categories: laboratory studies including $\mathrm{F}$ release, enamel solubility, and enamel $F$ uptake. Animal experiment assessed the anticaries effect of topically applied $F$ and release of $F$ from subcutaneously implanted alginate. Human studies involved $\mathrm{F}$ distribution from alginate impressions to saliva and circulatory system as well as alginate ingestion and inhalation of the alginate dust.

Review results: In vitro and in vivo findings indicated that alginate continuously released $\mathrm{F}$ in aqueous solution. Topical application of alginate resulted in significant enamel $\mathrm{F}$ uptake and reduced enamel solubility. Animal experiment showed that topically applied alginate resulted in a significant inhibition of caries. Subcutaneously implanted alginate continuously released $F$. Human studies revealed that $F$ in alginate impression are readily taken in and distributed to saliva and blood. Deliberately ingested alginate raised plasma $\mathrm{F}$ to considerable level. The $\mathrm{F}$ inhaled from emitted alginate dust did not elevate the plasma F level.

Conclusion: The outcome of this overview indicates that alginate impression materials are rich source of $\mathrm{F}$ delivery to dental tissues, oral fluids, and systemic circulation.

Clinical significance: The beneficial local effects of $\mathrm{F}$ in alginate impression materials have been discussed. On the other hand, alginate impressions elevate the plasma F levels if the pooled saliva is swallowed or part of the material is accidentally ingested. Dental professionals require to familiarize with these aspects.
\end{abstract}

Keywords: Alginate, Bioavailability, Biological fluids, Caries inhibition, Enamel, Fluoride release.

International Journal of Experimental Dental Science (2019): 10.5005/jp-journals-10029-1192

\section{INTRODUCTION}

Alginate is a soluble salt of alginic acid, a colloidal polysaccharide extracted from marine kelp (brown seaweed plant). The bioadhesive, biocompatible, biodegradable, nontoxic, and the sol/gel transition properties make alginates useful in the pharmaceutical industry as sustained, controlled-release drug delivery systems. ${ }^{1}$ Alginate impression material is an elastic irreversible hydrocolloid developed as a substitute for the agar (reversible hydrocolloid) when its supply became scarce during World War II. In dental practices, it is the most commonly used impression material due to its low cost, hydrophilic nature, ability to record details, and sufficient elastic recovery. The material is used to generate gypsum casts for making diagnostic casts, duplication of casts, provisional crowns and bridges, orthodontic study models, mouth guards, bleaching trays, and fabrication of removable prosthesis. Alginate impression is also suggested as a vehicle in the management of patient's gag reflex during dental treatment ${ }^{2}$ and antiseptic carrier in the treatment of oral infections. ${ }^{3}$ The $\mathrm{F}$ compounds in the form of sodium silicofluoride $\left(\mathrm{Na}_{2} \mathrm{SiF}_{6}\right)$, potassium titanium fluoride $\left(\mathrm{K}_{2} \mathrm{TiF}_{6}\right)$, and sodium/zinc fluorides are fundamental ingredients of alginate impression materials. They are incorporated to accelerate the setting reaction of gypsum products and aid in the production of casts with a hard, dense surface. ${ }^{4,5}$

Although alginate impression materials have been widely used in dental practices for three decades, it was not until 1978 when Hattab and Frostell first studied the local and systemic effects

\section{Essen, Germany}

Corresponding Author: Faiez N Hattab, Visiting Professor, Essen, Germany, Phone: +49 17625472979, e-mail:f_hattab@hotmail.com

How to cite this article: Hattab FN. Local and Systemic Effects of Fluoride in Alginate Impression Materials: A Review. Int J Experiment Dent Sci 2019;8(2):51-57.

Source of support: Nil

Conflict of interest: None

of $\mathrm{F}$ in alginate materials. ${ }^{6}$ They found that 10 brands of alginate impression materials contained $4.4-24.2 \mathrm{mg} / \mathrm{g} \mathrm{F}(0.44-2.42 \% \mathrm{~F})$ in the powder formulas. ${ }^{7,8}$ Analysis of seven alginate brands in the USA showed $\mathrm{F}$ concentrations ranged from $0.86 \%$ to $3.05 \%$. $^{9}$ Braga et al. ${ }^{10}$ found that seven alginate brands in Brazil contained $\mathrm{F}$ concentrations of $0.56-1.35 \%$.

The aim of this review is to highlight the effects and behavior of $F$ in alginate including release in water and acid, enamel solubility, enamel uptake, caries-inhibiting activity, transferred to saliva and blood, bioavailability of $\mathrm{F}$ from ingested alginate materials, and inhalation of alginate dust.

\section{Review Results}

\section{Release of Fluoride from Alginate Impression}

From the two brands of alginate powder contained 14,629 and $18,692 \mathrm{ppm}$ F, fluoride release was tested. Fresh alginate mix was loaded onto a perforated impression tray and submerged in unstirred 
deionized water. The F concentration was determined using the combined $\mathrm{F}^{-}$-selective electrodes. Results showed that an average of 1.7 and $6.3 \%$ of the $F$ content in the alginates leached out after 5 minutes and 3 hours, respectively. At 5 minutes, the released $F$ concentration averaged 10.7 ppm. ${ }^{7}$ Lee et al. ${ }^{11}$ reported that the alginate specimens released 12.6 or $14.8 \mathrm{ppm} F$ into water after 5 minutes of shaking, which contained $1 \%$ or $2 \%$ NaF. Cylindrical molds made from four alginate brands contained approximately $10 \mathrm{mg} F$ were submerged in separate beakers containing $100 \mathrm{~mL}$ of deionized water or $0.10 \mathrm{M} \mathrm{HCl}(\mathrm{pH} \sim 1)$ shaken at $90 \mathrm{rpm}$. At 3 hours, the mean $F$ released into water was $19.4 \pm 3.74 \%$ of the $F$ content in the molds. At 24 hours and 48 hours, the F release was $25.6 \pm 3.64 \%$ and $26.7 \pm 3.73 \%$, respectively. The corresponding data of $F$ released into acid solution at 3, 24, and 48 hours were $59.2 \pm 13.07 \%, 89.3 \pm$ $6.25 \%$, and $92.0 \pm 6.45 \%$, respectively. The amount of $F$ released into water at 48 hours was $2.67 \mathrm{mg}$ and $9.20 \mathrm{mg}$ in acid (Fig. 1). ${ }^{8}$ The rate of $\mathrm{F}$ release in acid solutions did not exceed 5 times that occurred in water at any time.

Whitford and Ekstrand ${ }^{12}$ tested $\mathrm{F}$ released from alginate cylinders contained $3.8 \mathrm{mg} F$ into $50 \mathrm{~mL}$ distilled water or $0.10 \mathrm{~N} \mathrm{HCl}$. They found that at 48 hours, the $F$ released in water was $0.50 \mathrm{mg}$ and $3.3 \mathrm{mg}$ in acid. They reported that at 48 hours, into water $0.50 \mathrm{mg}$ of $\mathrm{F}$ was released and into acid $3.3 \mathrm{mg}$. Braga et al. ${ }^{10}$ found the amount of $\mathrm{F}$ released from alginate molds was lower in saliva than in water. The continuous release of $\mathrm{F}$ from alginate in vitro was substantiated in vivo using rat experiments where subcutaneously implanted alginate released $\mathrm{F}$ for up to 3 weeks. ${ }^{9}$

\section{Effect of Alginates on Enamel Solubility}

Intact premolars extracted for orthodontic reasons were employed to evaluate the 4-mintue topical application of alginate impression materials contained 4.4, 14.6, and $18.7 \mathrm{mg} \mathrm{F/g}$ on enamel solubility resistance. Enamel surface area (window) were dipped in plastic cups containing $0.2 \mathrm{M}$ sodium acetate-acetic buffer $(\mathrm{pH} 4)$ and shaken for 20 minutes at room temperature. The amounts of calcium and phosphate dissolved prior to and post alginate treatment have been taken as a measure for enamel solubility reduction. In a parallel solubility experiment, enamel topically treated with alginate contained $1 \% \mathrm{~F}$ as $\mathrm{NaF}$ and acidulated phosphate fluoride (APF) gel (Gel II ${ }^{\circledR} 0.5 \% \mathrm{~F}, \mathrm{pH} 4.5$ to 5.0 ) which were exposed to a weak acetate buffer $(0.01 \mathrm{M}, \mathrm{pH} 4.0)$ for six successive demineralization runs. Significant $(p<0.01)$ reduction of enamel solubility in 0.2 acetate buffer ranged from $43 \%$ to $60 \%$ (Fig. 2). ${ }^{13}$ Figure 3 depicts the percentage of enamel solubility reduction in 0.01 acetate buffer with an EF exert of $50 \%$ antisolubility effect compared to $60 \%$ by Gel II throughout the demineralization runs.

\section{Enamel F Uptake from Alginate}

Extracted premolars were topically treated with alginate containing $18.7 \% \mathrm{~F}$ for 5 minutes. Encircled enamel area $\left(12.6 \mathrm{~mm}^{2}\right)$ delineated on the mesial and distal aspects of the buccal surface of each tooth crown. One served as the experiment and the other as the control. Enamel layers were biopsied using acid etch enamel microsampling technique, where $0.1 \mathrm{~mL}$ of $1 \mathrm{M} \mathrm{HClO}_{4}$ saturated with cotton pellet were applied for 15 seconds. The thickness of the biopsied enamel layer was calculated from the dissolved calcium and phosphate. Fluoride concentration was determined as $F(p p m)=F(\mu \mathrm{g}) \times 10^{6} \%$ enamel $\mu \mathrm{g} .{ }^{7,14}$ Alginate topical application resulted in significant $(p<$ 0.05 ) F uptake of 614 ppm in the outer $5.2 \mu$ m enamel layer. ${ }^{7}$ In human study, alginate impression increased the enamel $\mathrm{F}$ concentration to $695 \mathrm{ppm} .{ }^{15}$ Scanning electron microscopy of ground enamel topically treated with alginate revealed the adherence of the materials after acid etch and washing with water (Fig. 4).

\section{Effect of Alginate on Dental Caries}

Sprague-Dawley rats were divided into three groups; (I): rats treated with placebo alginate formula almost free of $F$, (II): 25 rats treated with alginate, (III): 24 rats treated with alginate supplemented by $3 \%$ chlorhexidine diacetate $(\mathrm{CH})$. The rats were fed with cariesconductive diet and infected with Streptococcus mutans each week throughout the 8-week experimental period. Prior the experiment, the rats were anesthetized by intramuscular injection Hypnorm ${ }^{\circledR}$ Vet (Leo, Sweden). Freshly prepared alginate mix contained 1\% $\mathrm{F}$ as $\mathrm{NaF}$ was loaded into disposable syringe with a metal nozzle that had a spoon-shaped end to fit the experimental left lower molars. Alginate was applied topically for 5 minutes, twice weekly,

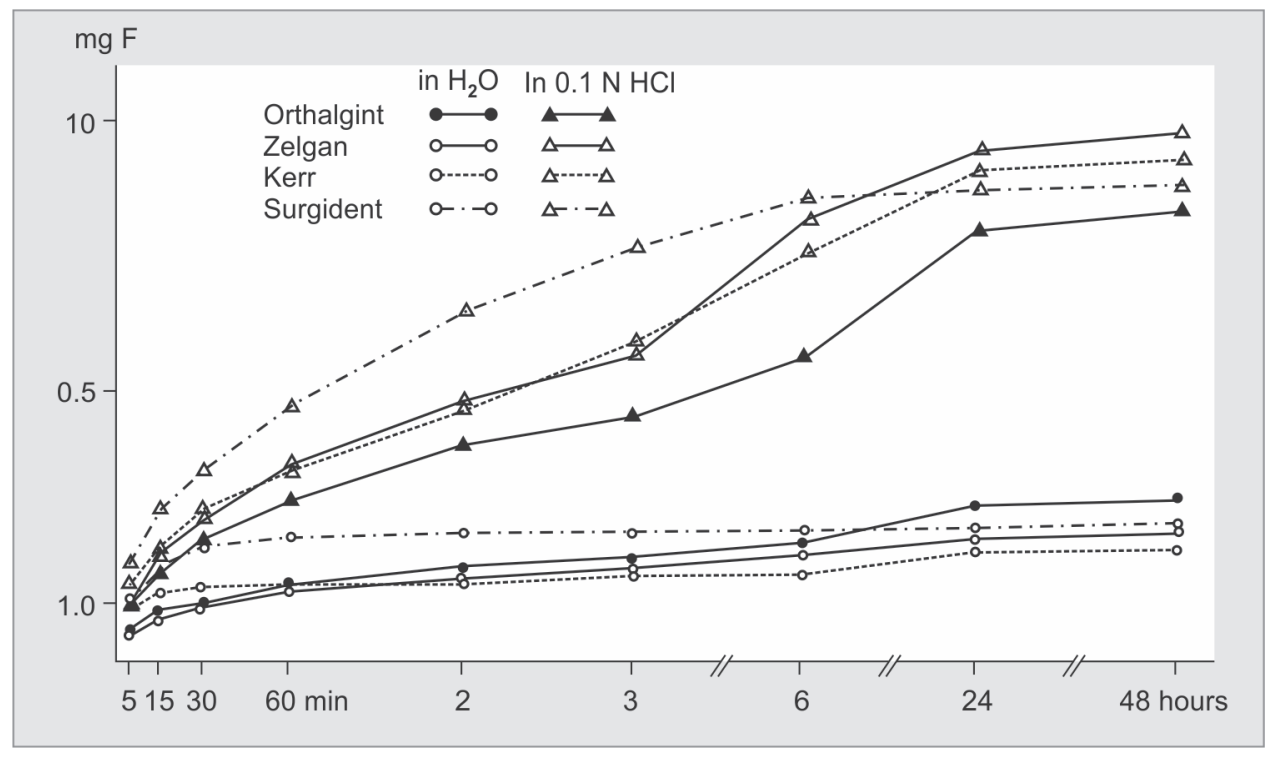

Fig. 1:The amount of $F(\mathrm{mg})$ diffused from cylindrical alginate's specimens. Each alginate specimen contained 10 mg F. The specimens submerged in beakers (one specimen per beaker) containing $100 \mathrm{~mL}$ deionized water or $0.10 \mathrm{~N} \mathrm{HCl}$ solution ${ }^{8}$ 
and up to a total of 16 applications. The contralateral side acts as a control. After 8 weeks' experiment, the treated side in groups II and III showed highly significant caries reduction compared to the untreated side $(p<0.001)$, with an average caries reduction of $45.8 \%$.

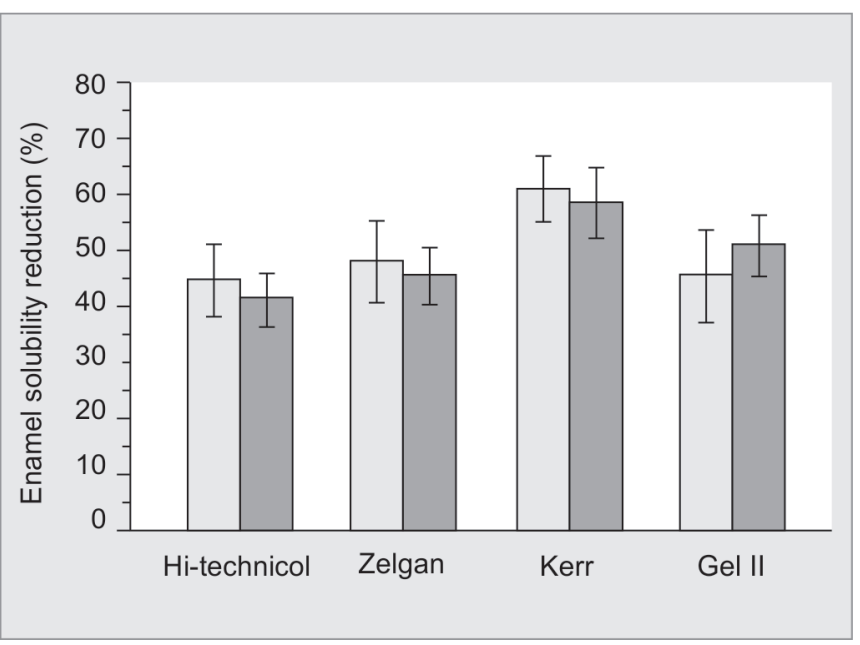

Fig. 2: Effect of alginates (three brands) and APF gel topically applied for 4-minute on reduction of enamel solubility in $0.2 \mathrm{M}$ acetate buffer at $\mathrm{pH}$ 4. The open columns represent the calcium data and the closed columns the phosphate data. The vertical bars in the center of each column show the standard deviation ${ }^{13}$

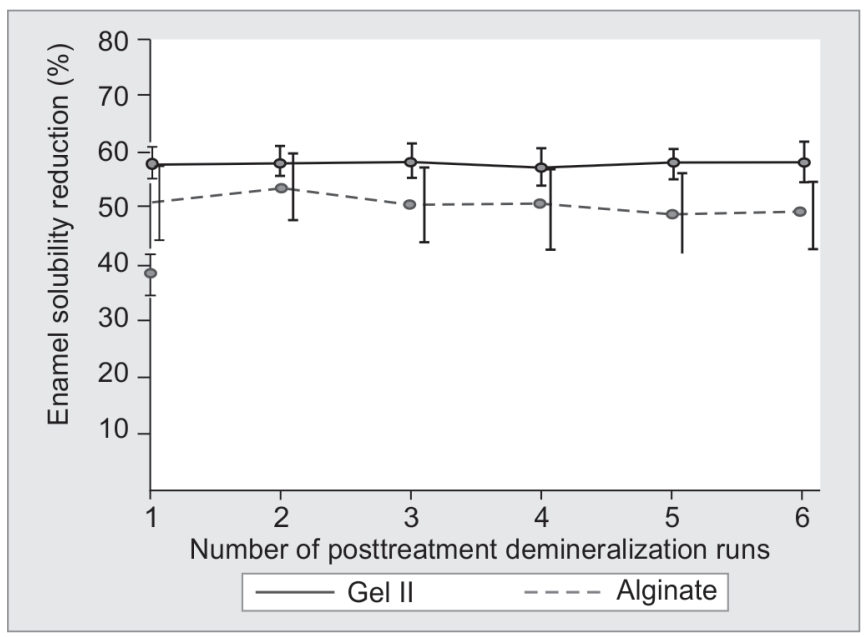

Fig. 3: Enamel solubility reduction of alginate ( $1 \% \mathrm{~F}$ as $\mathrm{NaF})$ and $\mathrm{APF}$ gel (Gel II 0.5\% F, pH 4.5-5.0) topically applied for 4-minute followed by successive demineralization runs in 0.01 acetate buffer. The bars represent standard deviations ${ }^{13}$
The coadministration of $\mathrm{F}$ and $\mathrm{CH}$ demonstrated a caries reduction of $12 \%$ greater than that of $\mathrm{F}$ alone. ${ }^{16}$ Examples of lower molars' morphology and sites of onset carious lesions in rats are depicted in Figure 5. The reduction in the scores of buccolingual caries is similar to that achieved by the daily topical application of gels containing $0.06 \%$ $\mathrm{F}$ (as NaF) for a 20 -day experiment period. ${ }^{17} \mathrm{Hefti}^{18}$ who applied $\mathrm{NaF}$ $(1.23 \% \mathrm{~F})$ on two occasions during the 20 -day experimental period reported a caries reduction in rats, which ranged from $45 \%$ to $68 \%$.

\section{Distribution of Alginate $\mathrm{F}$ to Saliva}

Maxillary alginate impressions were taken of four adult volunteers. Immediately prior to making impressions, saliva was stimulated by placing few drops of citric acid on the tip of the tongue. At removal of impression, the pooled saliva expectorated into a plastic graduated tube. Aliquots were taken at consecutive intervals, buffered, and $\mathrm{F}$ concentrations determined. The area under the curve (AUC) of saliva $\mathrm{F}$ concentration was determined. Findings indicated that the average salivary $F$ concentrations at zero-time interval and at 60 minutes were $74 \pm 15$ ppm $( \pm S D)$ and $0.66 \pm 0.25$ ppm, respectively (Fig. 6). The $F$ levels at 4 hours were still higher than the baseline value $0.015 \pm 0.005$ $\mathrm{ppm}$. The $\mathrm{AUC}_{0-1 \text { hour }}$ was $11.93 \pm 2.72 \mu \mathrm{g} \mathrm{F} \times$ hour $/ \mathrm{mL}{ }^{7}$ An experiment on five adult subjects who received alginate impressions showed that the salivary $\mathrm{F}$ levels were extremely variable and ranged from 15 to $380 \mu \mathrm{M}$ at 15 minutes sampling and averaged $132 \mu \mathrm{M}(2.5 \mathrm{ppm}){ }^{12}$ A study on children showed at 15 minutes and 30 minutes after alginate impressions, the $\mathrm{F}$ concentrations were $164 \mu \mathrm{M}$ and $89 \mu \mathrm{M} .^{15}$

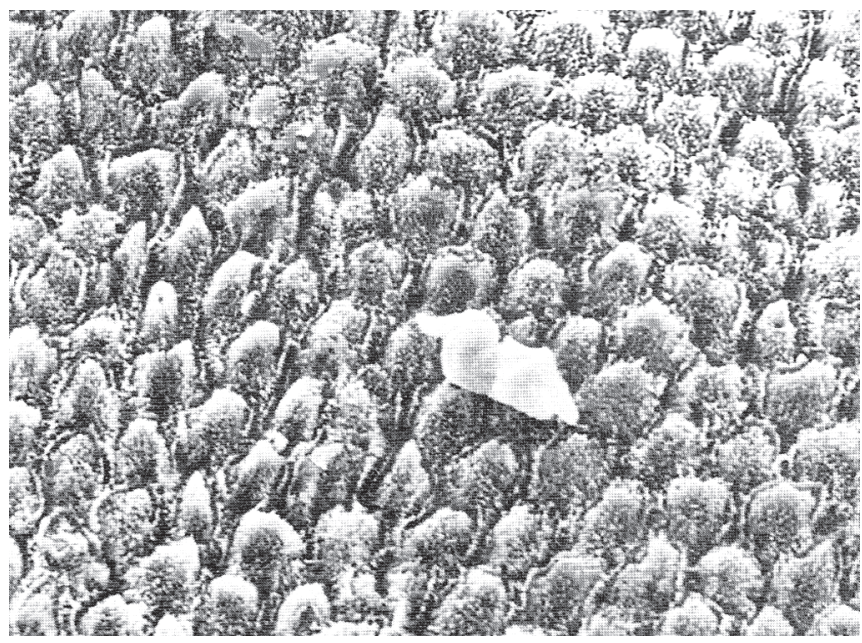

Fig. 4: SEM of ground enamel surface show the adherence of alginate remnant after topical application followed by acid etching and washing in water for 15 seconds $^{14}$
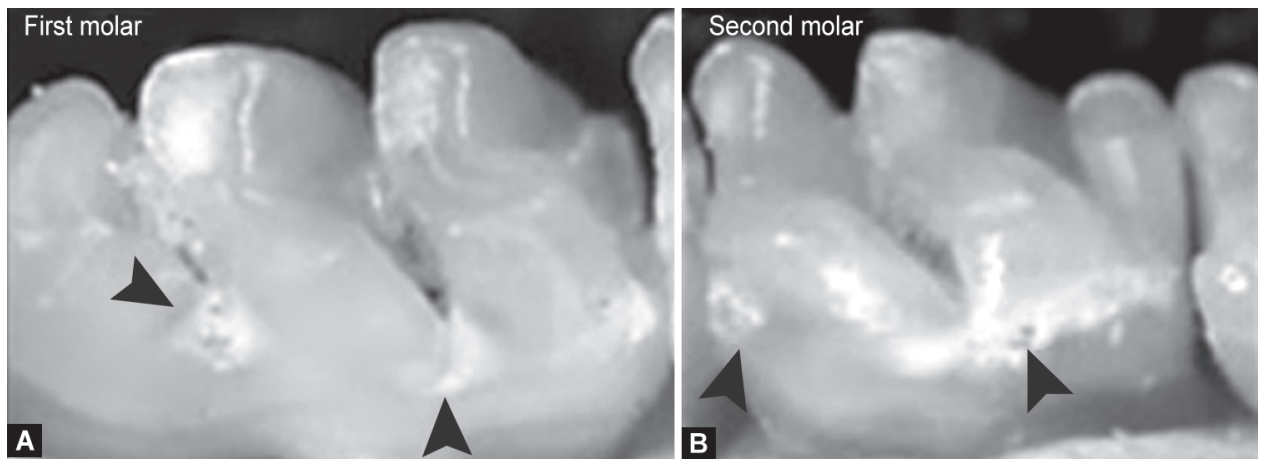

Figs 5A and B: Images of lower molars in rats showing the onset and severity of carious lesions indicated with arrow heads. [From: https://www. wbur.org/commonhealth/2016/08/01/nano-toothpaste-nano-mouthwash]. By Emma Betuel 


\section{Fluoride Transfer from Alginate Impression to Blood}

A study conducted on adult volunteer were approximately $15 \mathrm{~g}$ of alginate mix contained $18.7 \mathrm{mg}$ F/g loaded on stock tray. Single, double, and four maxillary alginate impressions were taken in separate occasions. Immediately followed impression taking, the stimulated pooled saliva was swallowed with a cup of water. Fingertip capillary blood samples were drawn at intervals of $15,30,45,75,180$, and 270 minutes. The blood sample transferred into microcentrifuge tubes contained heparin solution to prevent blood coagulation and the tubes were then centrifuged. Plasma F concentration was determined using $\mathrm{F}^{-}$-selective electrodes. In a separate experiment as a reference, the same subject swallowed $3 \mathrm{mg} \mathrm{F}$ (as $\mathrm{NaF}$ ) in aqueous solution. ${ }^{6,7}$ Systemic absorption and distribution of $F$ was a rapid event following impression taking. The peak plasma F level of $119 \mathrm{ng} \mathrm{F/mL}$ ( $0.119 \mathrm{ppm}$ ) and $200 \mathrm{ng} / \mathrm{mL}$ reached 30 minutes after single and double impressions, respectively. The plasma F level reached a peak of $224 \mathrm{ng} / \mathrm{mL}$ after 90 minutes for four impressions. The peak plasma $\mathrm{F}$ level of the F-reference solution was $150 \mathrm{ng} / \mathrm{mL}$ at 30 minutes

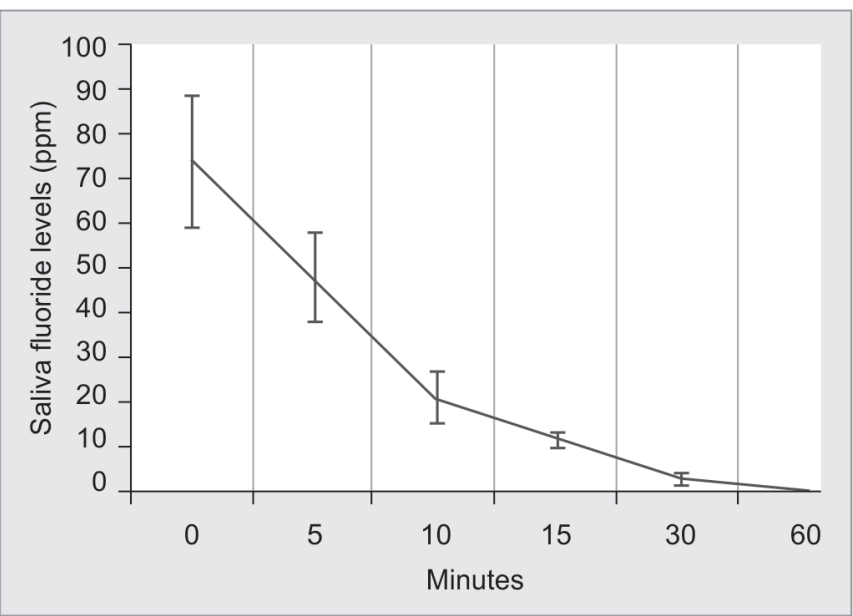

Fig. 6: Mean saliva fluoride concentration ( $\mathrm{ppm}$ ) in 4 subjects received maxillary alginate impressions. Bars indicate standard deviations ${ }^{7}$
(Fig. 7). The estimated $A_{U} C_{0-5 h o u r s}$ of $F$ concentrations after double impressions was $421 \mathrm{ng} \mathrm{F} \times$ hour $/ \mathrm{mL}$ compared to $315 \mathrm{ng} \mathrm{F} \times$ hour $/ \mathrm{mL}$ of the $\mathrm{F}$ reference solution. The baseline plasma $\mathrm{F}$ concentration averaged $13.5 \mathrm{ng} / \mathrm{mL}$. In a study of the systemic absorption of $F$ from maxillary and mandibular alginate impressions containing $14,950 \mathrm{ppm}$ and pooled saliva collected, the peak plasma $\mathrm{F}$ value of $1.69 \mu \mathrm{M}$ $(0.032 \mathrm{ppm})$ occurred at 0.5 hours after the impressions. At 4 hours, the plasma $\mathrm{F}$ levels averaged $0.86 \mu \mathrm{M}^{12}$

\section{Ingestion of Alginate Material}

After overnight fasting, adult volunteers' ingested $2 \mathrm{~g}$ of freshly set alginate containing $\sim 10 \mathrm{mg}$ F. Series of capillary blood samples were taken at intervals of 15-120 minutes, 3-9 hours and 18 hours. Urine was collected 24 hours before and at the end of the experiment. On separate occasion, the same subjects ingested $3 \mathrm{mg} \mathrm{F}$ as $\mathrm{NaF}$ reference solution. The bioavailability of $\mathrm{F}$ from ingested alginate, AUC (ng $\mathrm{F} \times$ hour $/ \mathrm{mL}, 0-18$ hours), compared to the reference $F$ solution, was calculated using the following equation: $f_{\text {rel }} \%=$ $\Delta \mathrm{AUC}_{\mathrm{alg}} \times D_{\mathrm{NaF}} \times 100 / \Delta \mathrm{AUC} C_{\mathrm{NaF}} \times D_{\text {alg }}$, where $f_{\text {rel }}$ is the relative bioavailability, $D_{\text {alg }}$ is the amount of $\mathrm{F}$ in the alginate, and $D_{\mathrm{NaF}}$ is the amount of $\mathrm{F}$ in the $\mathrm{NaF}$ reference solution. The peak plasma F levels of 120-158 ng/mL had reached 30-120 minutes after alginate ingestion (Fig. 8), while the peak plasma F levels of $140-176 \mathrm{ng} / \mathrm{mL}$ was attained at 30 minutes following the swallowing of $3 \mathrm{mg} F$ reference solution (Fig. 9). The mean $A C_{0-18 \text { hours }}$ of ingested alginate was 661 $\pm 275 \mathrm{ng} \times$ hour $/ \mathrm{mL}$. During 24 hours, $23.6 \pm 8.5 \%$ of the $F$ dosage in alginate was excreted in urine. Twice as much were excreted after swallowing $3 \mathrm{mg} F$ reference solution. The calculated $\mathrm{F}$ bioavailability from plasma data was $59 \pm 23 \%( \pm S D) .{ }^{8}$ In an experiment of deliberate ingestion of $2.7 \mathrm{~g}$ alginate, the highest plasma values occurred between 1.5 hours and 2 hours and averaged $6.85 \mu \mathrm{M}$ $\left(0.13\right.$ ppm). ${ }^{12}$

\section{Inhalation of Alginate Dust}

Five dental personnel aged 24-35 years participated in the study. Alginate containers were shaken and tumbled for about 30 seconds and immediately opened followed by preparing several alginate

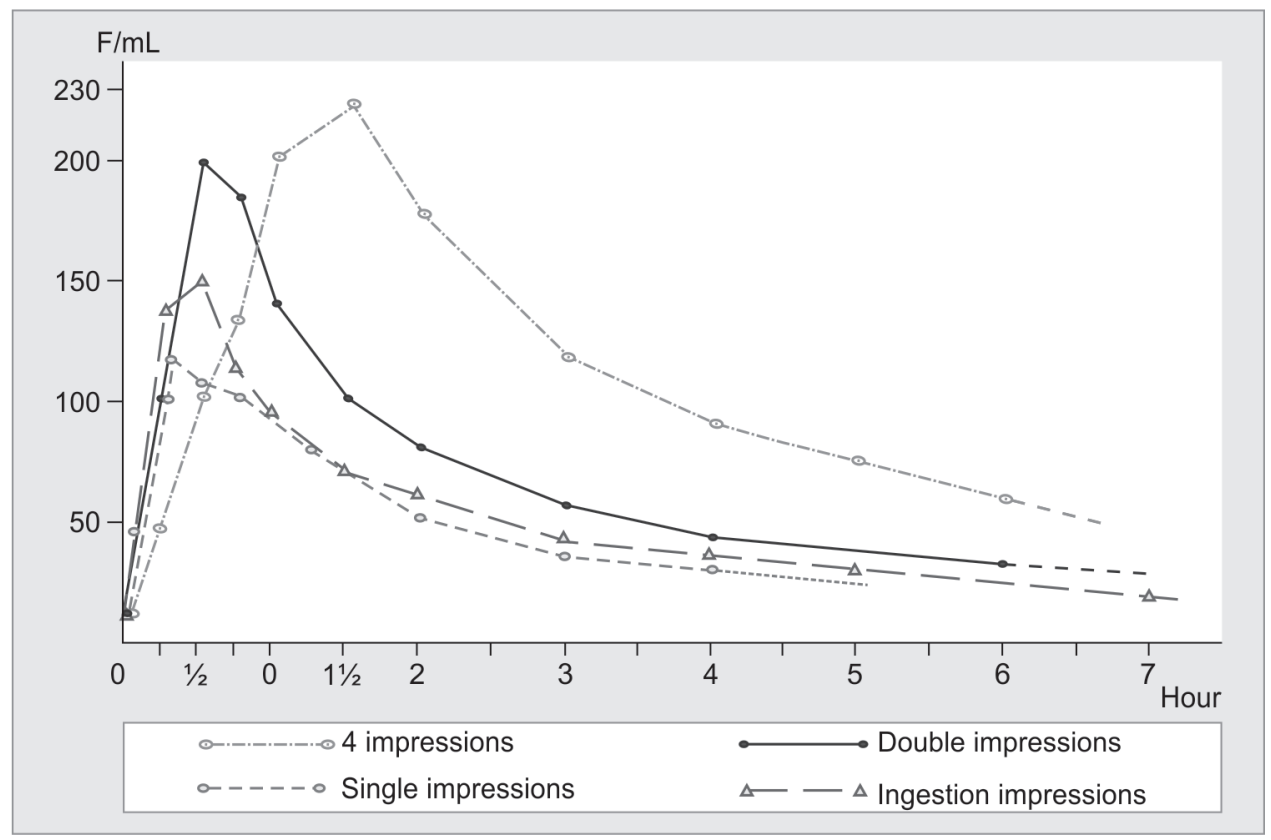

Fig. 7: Plasma fluoride concentrations $(\mathrm{ng} / \mathrm{mL})$ after alginate impressions compared with swallowed $3 \mathrm{mg} \mathrm{F}$ as $\mathrm{NaF}_{\text {reference solution }}^{7}$ 


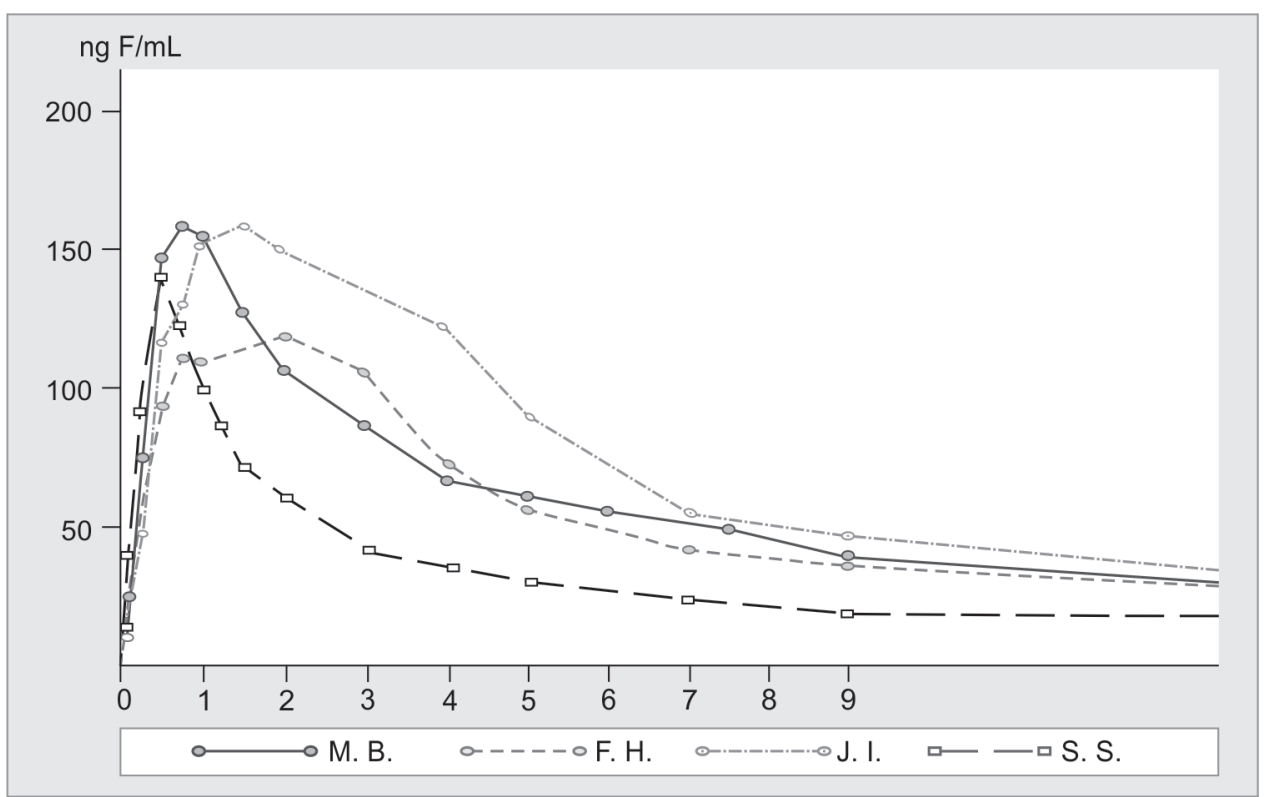

Fig. 8: Plasma fluoride concentration $(\mathrm{ng} / \mathrm{mL})$ in 4 subjects ingested of $2 \mathrm{~g}(\sim 10 \mathrm{mg} \mathrm{F})$ alginate ${ }^{8}$

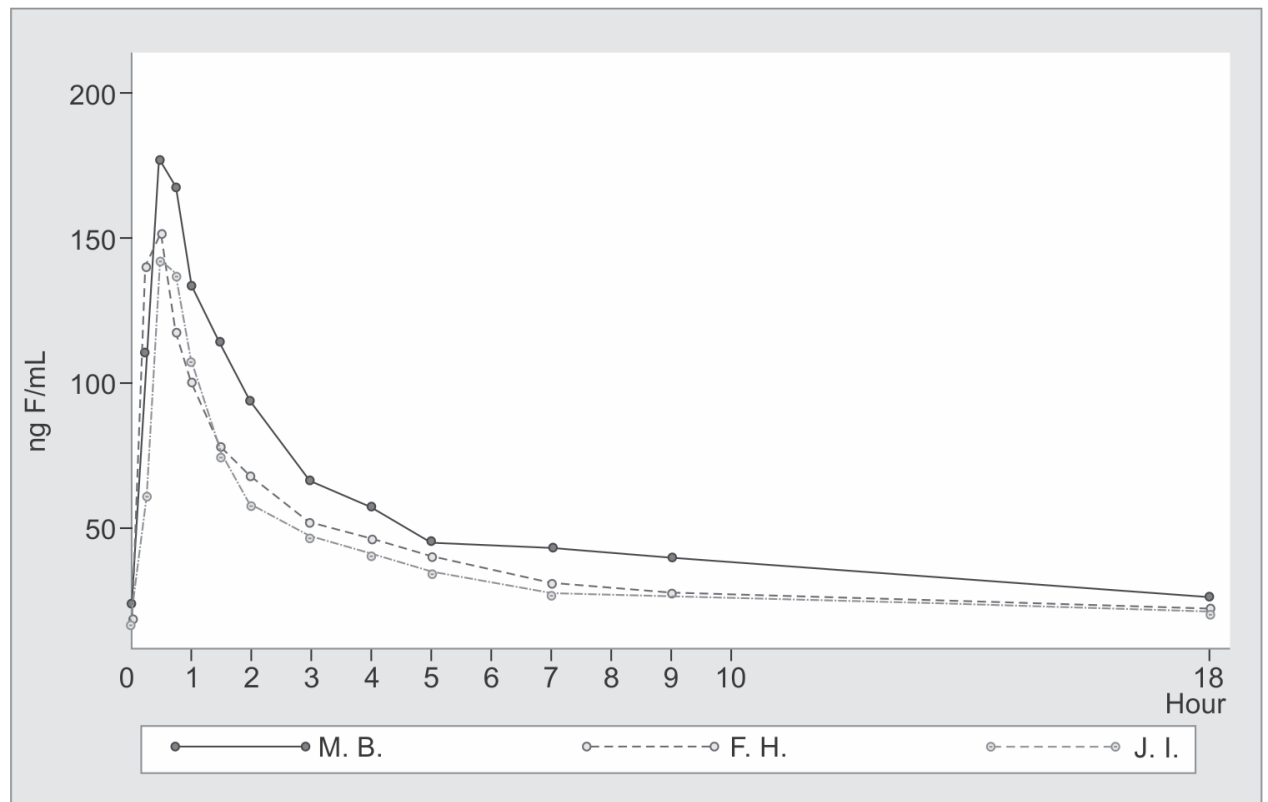

Fig. 9: Plasma fluoride concentrations $(\mathrm{ng} / \mathrm{mL})$ in 3 subjects swallowed $3 \mathrm{mg}$ of $\mathrm{F}$ as $\mathrm{NaF}$ reference solution ${ }^{8}$

mixes during 15 minutes. Fingertip capillary blood samples were taken before and immediately after the working session. Findings showed that plasma $\mathrm{F}$ concentrations were within the physiological baseline values of 10 and $20 \mathrm{ng} \mathrm{F/mL.}{ }^{8}$ No other studies on this subject are available for comparison.

\section{Discussion}

Alginate is the most frequently used impression materials in dental practices. They contain $1-3 \% \mathrm{~F}$ in different $\mathrm{F}$ compounds. The effects of $F$ in alginate materials have received little attention and most dentists and dental hygienist are unaware of its effects. This review provides an overview of the state of $\mathrm{F}$ in the materials and its local and systemic effects.

\section{Release of Fluoride from Alginate}

The release of $F$ from fluoridated materials are influenced by several factors including solubility, type of F compounds, porosity, nature of the dissolving medium, temperature, surface area, and F complication with secondary ingredients. ${ }^{19,20}$ Experiments have demonstrated that $\mathrm{F}$ released from alginate molds into acid $(0.1 \mathrm{M} \mathrm{HCl})$ at 3 and 48 hours was 3.05 and 3.45 times greater than that released into water (Fig. 1). In testing one alginate brand, Whitford and Ekstrand ${ }^{12}$ reported that the rate of $\mathrm{F}$ diffusion into $0.10 \mathrm{~N} \mathrm{HCl}$ was approximately 10 times greater at all time points. The figures given in their report at 48 hours diffusion were $0.50 \mathrm{mg} \mathrm{F}$ into water and $3.3 \mathrm{mg} F$ into acid. Thus, the actual ratio of $F$ diffusion in acid was only 6.6 times greater than that released into water. 


\section{Enamel Solubility and Enamel F Uptake}

In vitro topical alginates exerted a significant reduction in enamel solubility which was comparable to APF Gel II ${ }^{\circledR}$ (Figs 2 and 3) and significantly increased the enamel $F$ uptake. No direct relationship was found between $F$ contents in the applied products and both enamel antisolubility and F uptake. ${ }^{13,14}$ This is due to the differences in the physicochemical properties of the materials. ${ }^{19-21}$ In parallel, Seppä ${ }^{22}$ reported that the efficacy of $F$ varnishes was not proportional to their $\mathrm{F}$ concentrations and that enamel solubility was not directly proportional to the $F$ content of the enamel. Clinical data concluded that increase in the $\mathrm{F}$ concentration of a product will not linearly increase its anticaries' effectiveness. ${ }^{23}$

\section{Alginate and Salivary F Levels}

Fluoride in saliva is a F delivery source to dental plaque, tooth surfaces, and remineralization process. Reports indicated that low salivary $F$ level of around $0.04 \mathrm{ppm}$ exerts significant protection against dental caries, ${ }^{24}$ inhibition of demineralization, and promotion of remineralization. ${ }^{25}$ Salivary $\mathrm{F}$ concentration (AUC $_{0-1 \text { hour }} 11.93 \pm 2.72 \mu \mathrm{g} \mathrm{F} \times$ hour $/ \mathrm{mL}$ ) following alginate impression is about 32 times greater than chewing one stick of a gum (Fluogum ${ }^{\circledast}$ ) containing $0.250 \mathrm{mg} \mathrm{NaF}^{26}$ The peak salivary $\mathrm{F}$ concentration at zero time (74 ppm) is 8.2 times greater than that reported for $\mathrm{F}$ dentifrice application $(9.03 \mathrm{ppm}){ }^{26}$ Following alginate impression containing $14,950 \mathrm{ppm} F$, Whitford and Ekstrand $^{15}$ reported a peak salivary F value of $380 \mu \mathrm{M}(7.22 \mathrm{ppm})$ at 15 minutes. This led them to conclude that their values were 15.4 times lower than that reported by Hattab and Frostell. ${ }^{6}$ In this short communication, the peak $\mathrm{F}$ level was determined at zero time in stimulated saliva of one subject who received alginate impression containing 18,692 ppm F. Subsequent experiment on four subjects showed the average $F$ peak was $33 \%$ less than the value obtained from one subject. ${ }^{7}$ The salivary $F$ concentration at zero time was 6.4 times higher than that at 15 minutes' interval (Fig. 6). Differences in the experimental procedures render such comparison irrelevant. It well documented that the salivary $F$ levels following $F$ application showed great variability between subjects and salivary flow rates and that the $\mathrm{F}$ level sharply declined with time. ${ }^{7,27-29}$

\section{Fluoride Transfer to Blood}

The systemic absorption of $F$ following alginate impressions and swallowing stimulated pooled saliva was rapid. The peak plasma F level of $0.119 \mathrm{ppm}(6.26 \mu \mathrm{M}$ or $119 \mathrm{ng} / \mathrm{mL})$ was attained after 30 minutes (Fig. 8). The $A \cup C_{0-5}$ hours of the double impressions was 1.3 times greater than the intake of $3 \mathrm{mg} \mathrm{F}$ when $\mathrm{NaF}$ was used as the reference solution. ${ }^{7}$ Our experiment setup attempted to approximate the situation in children who cannot master their swallowing reflex during topical $\mathrm{F}$ application. Ekstrand et al. ${ }^{30}$ reported that $76 \%$ of the $\mathrm{F}$ in APF gel applied to children has been ingested, which in turn raised the plasma $F$ concentration levels to $300-1,443 \mathrm{ng} / \mathrm{mL}$. Whitford and Ekstrand ${ }^{12}$ reported that following alginate impressions and the collection of saliva (evacuated), the peak plasma F value was $1.69 \mu \mathrm{M}(0.032 \mathrm{ppm})$. They claimed that the peak plasma $\mathrm{F}$ level was 4.4 times lower than that found by Hattab and Frostell; ${ }^{6}$ while the correct figure should be 3.70 times lower (1.69 $\mu \mathrm{M}$ vs 6.26 $\mu \mathrm{M})$. Angmar-Månsson et al. ${ }^{31}$ found enamel fluorosis in rats exposed to transient daily peak plasma $\mathrm{F}$ levels of $10 \mu \mathrm{M}$ for 1 week.

\section{Ingestion of Alginate Material}

Ingested alginate raised the plasma $\mathrm{F}$ to peak levels, i.e., it ranged between 120 and $158 \mathrm{ng} / \mathrm{mL}$ and occurred from 30 minutes to 120 minutes after ingestion (Fig. 8). The delayed $\mathrm{F}$ peak and prolonged plasma F profile curves could partly be due to the high calcium content in the material (14-20\% calcium sulfate), which complexes $\mathrm{F}$ and delayed its absorption from gastrointestinal tract. However, more than $50 \%$ of $\mathrm{F}$ in alginate was bioavailable and reached the systemic circulation. It is interesting to find that the amount of $F$ diffused from alginate specimens into the acid solution after 3 hours was similar to the systemic $F$ bioavailability following alginate ingestion. As far as $\mathrm{F}$ is concerned, it is surprising that the Safety Data Sheet by the alginate manufacturers declared that "ingestion of material is probably not harmful if swallowed". 32,33 Barnes product $P / L$ dental alginates stated that "The material has NOT been classified by EC Directives or other classification systems as harmful by ingestion". ${ }^{34}$ Ormco Corporation reported "No known significant effects or critical hazards" of alginate ingestion. ${ }^{35}$ It has been reported that single ingestion of $0.1-0.3 \mathrm{mg} \mathrm{F} / \mathrm{kg}$ body weight produces early symptoms of acute $\mathrm{F}$ poisoning, which include gastric pain, nausea, vomiting, and headache. ${ }^{36}$

\section{Inhalation of Alginate Dust}

In order to achieve a uniform distribution of the ingredients in alginate powder, the container should be thoroughly shaken prior to the dispensing process. On opening the container and during mixing, dust evolved in the ambient air. The potential toxicity of alginate attracted special attention. de Freitas ${ }^{37}$ and Braga et al. ${ }^{10}$ analyzed several elements in dental alginate powders. They assumed health hazards due to $\mathrm{F}$ inhalation during alginate handling. Human experiment showed that the plasma $F$ levels following intensive alginate working session was within the physiological limits. ${ }^{8}$ Because no other data are available on this topic, it is difficult to compare the results with others. However, Brune and Beltesbrekke ${ }^{38}$ found the levels of dust collected $40 \mathrm{~cm}$ above containers of alginate powder that been shaken for 30 seconds and immediately opened were $1.3-2 \mathrm{mg} / \mathrm{m}^{3}$. Assuming $2 \mathrm{mg} / \mathrm{m}^{3}$ of alginate dust contained $3 \%$ of $\mathrm{F}$ emitted during alginate processing, it can be calculated that the emitted $F$ in the ambience air is only $0.06 \mathrm{mg} / \mathrm{m}^{3}$. A study of aluminum plant by Ehrnebo and Ekstrand ${ }^{39}$ revealed that workers exposed to dust contained $0.31 \mathrm{mg} \mathrm{F} / \mathrm{m}^{3}$ increased plasma $\mathrm{F}$ level 2.1 times greater than the baseline value, which is 5 times more than the assumed value for alginate. Thus, it supports the undetectable change in plasma $F$ level from inhaled alginate dust. On the other hand, alginate powders contain up to $26 \%$ free crystalline silica in the form of airborne particles that cause serious health problems, particularly to the respiratory system in unprotected individuals. It has been found that among workers who used safety masks $F$ inhalation reduced to $30-40 \%$ compared to those who did not use any mask. ${ }^{39}$

\section{Conclusion}

Alginate impression materials are important sources of $F$ release, which are taken up by dental hard tissues and transferred to oral fluids and systemic circulation. They vary in their F contents and abilities to deliver $F$. The present review showed that $F$ in alginate impressions exerts significant increase in enamel $F$ concentration, enhancing resistance to acid demineralization and inhibiting dental caries. On the other hand, alginate impression elevates the plasma 
F levels if the pooled saliva allowing to be swallow or if part of the materials was accidentally ingested. Manufacturers are required to declare the $\mathrm{F}$ content in the formulas and revise their safety data sheet regarding the hazard of ingesting the material. The readily distributed $F$ from alginate impression justifies an efficient saliva suctioning and careful inspection of the retained alginate debris in the mouth. This practice is recommended, especially for children, to avoid the risk of $\mathrm{F}$ overdosage. It is important to emphasize that personnel handling of alginate material should always wear the mask, so that the personnel can be protected against the evolved airborne particles.

\section{References}

1. Jain D, Bar-Shalom D. Alginate drug delivery systems: application in context of pharmaceutical and biomedical research. Drug Dev Ind Pharm 2014;40(12):1576-1584. DOI: 10.3109/03639045.2014. 917657.

2. Hattab FN, Duwayri ZN. Management of patient's gag reflex in making an irreversible hydrocolloid impression. J Prosthet Dent 1999;81(3):369. DOI: 10.1016/S0022-3913(99)70282-9.

3. Hesselgren SG. Method of applying preventive and therapeutic agents. US3964164 A 1976. encrypted.google.com/patents/ US3964164.

4. Craig RG. Review of dental impression materials. Adv Dent Res 1988;2(1):51-64. DOI: 10.1177/08959374880020012001.

5. Anusavice KJ, Kenneth J. Phillips' Science of Dental Materials, 11th ed. Elsevier; 2003. pp. 210-230.

6. Hattab F, Frostell $\mathrm{G}$. The release of fluoride from alginate impression materials. Community Dent Oral Epidemiol 1978;6(5):273-274. DOI: 10.1111/j.1600-0528.1978.tb01164.x.

7. Hattab F, Frostell G. The release of fluoride from two products of alginate impression materials. Acta Odontol Scand 1980;38(6):385-395. DOI: 10.3109/00016358009033609.

8. Hattab F. Absorption of fluoride following inhalation and ingestion of alginate impression materials. Pharmacol Ther Dent 1981;6(3-4): 79-86.

9. Whitford GM, Ekstrand J, Callan RS, et al. Subcutaneously implanted alginate as a continuous-release source of fluoride. J Dent Res 1980;59(2):186-191. DOI: 10.1177/00220345800590021901.

10. Braga AS, Catirse ABC, Vaz LG, et al. Quantitative analysis of fluorides in alginates for dental use. J Basic Appl Pharm Sci 2005;26(3):181-188.

11. Lee YK, Lim BS, Kim CW. Effect of fluoride addition on the properties of dental alginate impression materials. J Mater Sci Mater Med 2004;15(3):219-224. DOI: 10.1023/B:JMSM.0000015481.04144.57.

12. Whitford GM, Ekstrand J. Systemic absorption of fluoride from alginate impression material in humans. J Dent Res 1980;59(5):782-785. DOI: 10.1177/00220345800590050601.

13. Hattab F. Effect of fluoride-containing alginates and gels on the acid resistance of demineralized human enamel. Acta Odontol Scand 1984;42(3):175-181. DOI: 10.3109/00016358408993869.

14. Hattab FN, Wei SHY. Chemical changes and surface morphology of acid-etching of human enamel treated with topical fluoride agents in vitro. Caries Res 1987;21:282-293. DOI: 10.1159/000261057.

15. LeCompte EJ, Whitford GM. The biologic availability of fluoride from alginate impressions and APF gel applications in children. J Dent Res 1981;60(4):776-780. DOI: 10.1177/00220345810600040201.

16. Hattab F. Effect of topical application of alginate containing fluoride or fluoride and chlorhexidine on dental caries in rats. Caries Res 1984;18(4):367-374. DOI: 10.1159/000260789.

17. Regolati B, Schmid R, Mühlemann HR. Combination of chlorhexidine and fluoride in caries prevention. An animal experiment. Helv odont Acta 1974;18:12-16.
18. Hefti A. Effect of topical fluoride gel application on caries incidence in rats. Caries Res 1982;16(1):77-79. DOI: 10.1159/000260580.

19. Hattab F, Lindén L-Å. Diffusion of fluoride from alginate compared with other topical fluoride agents. Scand J Dent Res 1985;93(3):269-275. DOI: 10.1111/j.1600-0722.1985.tb01956.x.

20. Margolis HC, Moreno EC. Physicochemical perspectives on the cariostatic mechanisms of systemic and topical fluorides. J Dent Res 1990;69:606-613. DOI: 10.1177/00220345900690S119.

21. Wiegand A, Buchalla W, Attin T. Review on fluoride-releasing restorative materials-fluoride release and uptake characteristics, antibacterial activity and influence on caries formation. Dent Mater 2007;23(3):343-362. DOI: 10.1016/j.dental.2006.01.022.

22. Seppä L. Effects of a sodium fluoride solution and a varnish with different fluoride concentrations on enamel remineralization in vitro. Scand J Dent Res 1988;96(4):304-309. DOI: 10.1111/j.1600-0722.1988. tb01560.x.

23. Mellberg JR. Evaluation of topical fluoride preparations. J Dent Res 1990;69:771-779. DOI: 10.1177/00220345900690S149.

24. Featherstone JDB. Prevention and reversal of dental caries: role of low level of fluoride. Community Dent Oral Epidemiol 1999;27(1):31-40. DOI: 10.1111/j.1600-0528.1999.tb01989.x.

25. Lynch RJM, Navada R, Walia R. Low-levels of fluoride in plaque and saliva and their effects on the demineralisation and remineralisation of enamel; role of fluoride toothpastes. Int Dent J 2004;54(5 Suppl 1):304-309. DOI: 10.1111/j.1875-595X.2004.tb00003.x.

26. Hattab FN, Green RM, Pang KM, et al. Effect of fluoride-containing chewing gum on remineralization of carious lesions and on fluoride uptake in man. Clin Prev Dent 1989;11(6):6-11.

27. Zero DT, Fu J, Espeland MA, et al. Comparison of fluoride concentrations in unstimulated whole saliva following the use of a fluoride dentifrice and a fluoride rinse. J Dent Res 1988;67(10):1257-1262. DOI: 10.1177/00220345880670100201.

28. Oliveby A, Ekstrand J, Lagerlof F. Effect of salivary flow rate on salivary fluoride clearance after use of a fluoride-containing chewing gum. Caries Res 1987;21(5):393-401. DOI: 10.1159/000261045.

29. Hattab FN, Baghdady VS, Ghose LJ. Effect of sodium fluoride mouthrinsing on enamel solubility and levels of fluoride in enamel and in whole saliva. J Int Assoc Dent Child 1987;18(2):29-35.

30. Ekstrand J, Koch G, Lindgren LE, et al. Pharmacokinetics of fluoride gels in children and adults. Caries Res 1981;15(3):213-220. DOI: 10.1159/000260517.

31. Angmar-Månsson B, Ericsson Y, Ekberg O. Plasma fluoride and enamel fluorosis. Calcif Tissue Res 1976;22(1):77-84. DOI: 10.1007/ BF02010348.

32. DENTSPLY/Caulk. Safety Data Sheet/alginate. From: [https:// marketing.msdsonline.com/library/NHI/NHI997.pdf].

33. Henry Schein. Safety Data Sheet /alginate. From: [https://www. henryschein.ca/MSDS/1051602.pdf].

34. Dental Alginate/Barnes Products P/L. Safety Data Sheet. From: https:// www.schoolartsupplies.com.au/assets/files/ADENTAL_5247-02\%20 (1).pdf].

35. Ormco Corporation. Safety Data Sheet/alginate. From: [https://ormco. com/download/msds-basis-alginate-impression-materials].

36. Wei SHY, Hattab FN. Water fluoridation, systemic fluorides, and fluoride metabolism. In: Wei SHY, ed. Pediatric Dentistry: Total Patient Care. Philadelphia: Lea \& Febiger; 1988.

37. de Freitas JF. Potential toxicants in alginate powders. Aust Dent $J$ 1980;25(4):224-228. DOI: 10.1111/j.1834-7819.1980.tb03870.x.

38. Brune $\mathrm{D}$, Beltesbrekke $\mathrm{H}$. Levels of airborne particles resulting from handling alginate impression material. Scand J Dent Res 1978;86(3):206-210. DOI: 10.1111/j.1600-0722.1978.tb01933.x.

39. Ehrnebo M, Ekstrand J. Occupational fluoride exposure and plasma fluoride levels in man. Int Arch Occup Environ Health 1986;58(3):179-190. DOI: 10.1007/BF00432099. 